5 Price RW, Posner JB. Chronic paroxysmal hemicrania: a disabling headache syndrome responding to indomethacin. Ann Neurol 1978:3:183-4.

6 Thévenet JP. Delastrain MC, Dordain G. Hémicranie paroxystique chronique sensible à lindométacine. Presse Méd 1983:12:2855-8.

7 Geaney DP. Indomethacin-responsive episodic cluster headache. $J$ Neurol Neurosurg Psvchiatry 1983:46:860-1.

8 Bogucki A. Niewodniczy A. Case report: chronic cluster headache with unusual high frequency of attacks. Differential diagnosis with chronic paroxysmal hemicrania. Headache 1984:24:150-1.

Accepted 15 June 1987

Chronic paroxysmal hemicrania, episodic cluster headache and classic migraine in one patient

Sir: Cluster headache has a prevalence of $2 \cdot 4 / 1000 .{ }^{1}$ The reported male to female ratio is between 4.5 and $12.6: 1$ in different series. ${ }^{12}$ There is no increased incidence of migraine, either in the cluster headache patients or in their families. ${ }^{3-5}$

Chronic paroxysmal hemicrania is a much rarer disorder, with less than 40 patients reported in the world literature in $1983 .^{6}$ Recorded cases have been almost exclusively in women. A dubious "pre-chronic paroxysmal hemicrania stage" is described, where patients have rather atypical tension or migraine headaches; this occurred in five of eight patients reported by Sjaastad. ${ }^{7}$ Rapaport has recorded chronic paroxysmal hemicrania in a patient with classical migraine earlier in life, and there have been three possible cases of chronic paroxysmal hemicrania in patients with cluster headache. $^{89}$

Although chronic paroxysmal hemicrania is sometimes regarded as a variant of cluster headache, there is no evidence that cluster headache predisposes to chronic paroxysmal hemicrania, nor that chronic paroxysmal hemicrania occurs with increased frequency in migraine or cluster headache patients. We have found no recorded example of a single instance of the three syndromes in the same individual. We record the possibly unique instance of a patient with classical migraine, cluster headache and chronic paroxysmal hemicrania occurring independently over a 40 year period.

A 58 year old man presented in 1978 with a two year history of episodic headaches. They occurred every two weeks, but there were also bouts in which he had attacks daily for 3 to 4 days, notably more frequent in the evenings and occasionally at night. Alcohol would precipitate attacks. They started without aura as a severe localised throbbing pain in the left eye radiating to the left forehead which was tender and felt hot. During attacks the left eye watered and was visibly bloodshot. They lasted 30 to 120 minutes. There was no nausea or vomiting, or disturbance of vision. General health was good; he smoked cigars, and drank $1 / 4$ bottle whisky a day.

He gave a history of attacks of migraine from the age of 16 years until 20 in which he had expanding flashing lights in either visual field, followed in half an hour by throbbing unilateral headache, nausea and prostration for 18 to 24 hours. These occurred irregularly perhaps 3 or 4 times a year. His mother had suffered from "severe migraine", but there was no other past illness or family history of note.

No abnormality in the CNS was found except for left sided ptosis suggesting a mild Horner's syndrome. He had frequent extrasystoles, but no other abnormality in the heart, neck vessels, peripheral pulses, chest or abdomen. Blood pressure was $150 / 85 \mathrm{~mm}$ $\mathrm{Hg}$.

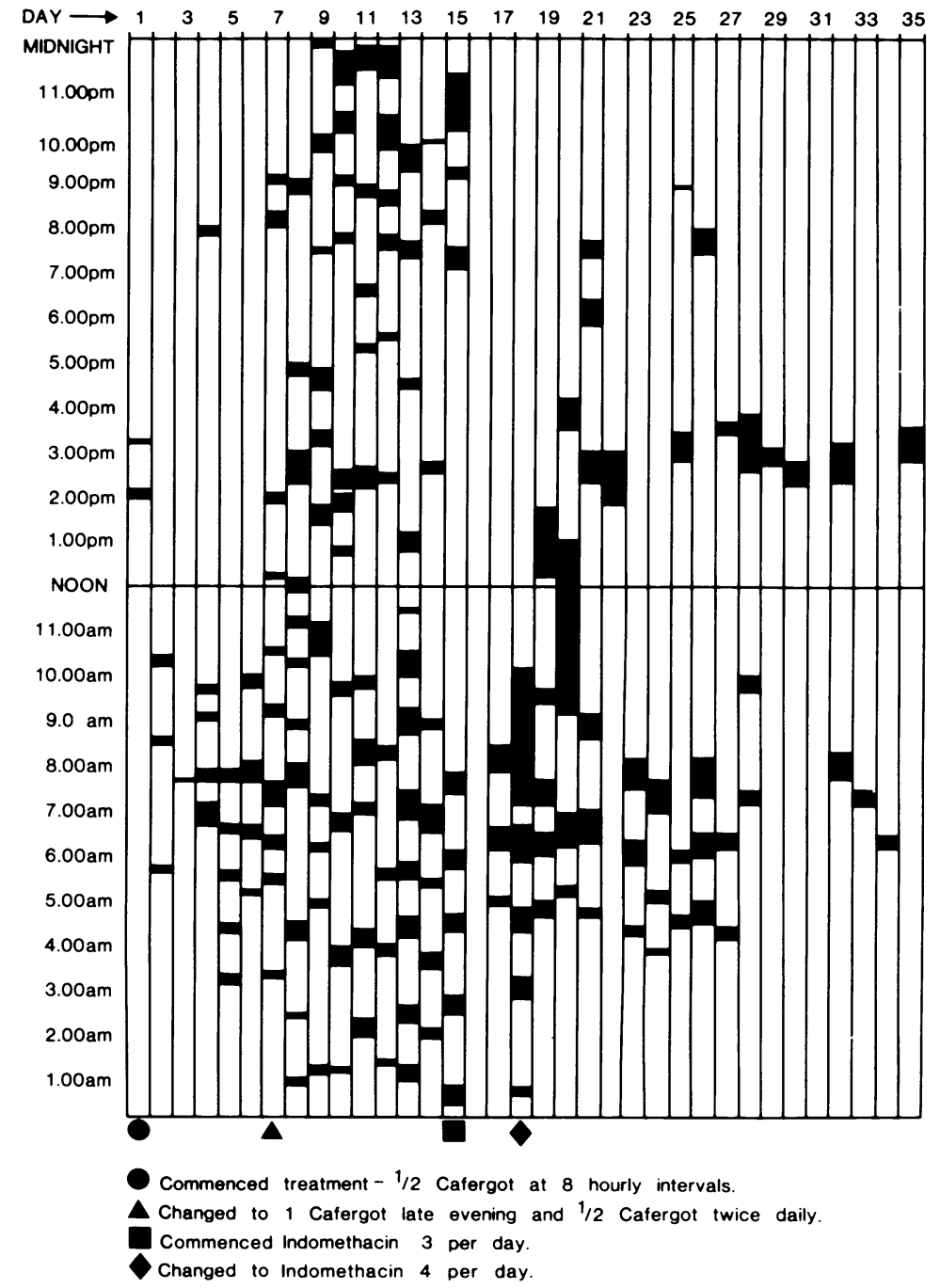

Fig Daily record of duration and intensity of episodic paroxysmal hemicrania. Attacks ceased on day 36. 
A diagnosis of cluster headache was made, the attacks being clearly different from the classic migraine of earlier years which had ceased at the age of 20 . He was advised to eliminate alcohol during clusters. Half of an ergotamine tartrate suppository $(1 \mathrm{mg})$ was given 8 to 12 hourly in an attempt to anticipate attacks. Symptoms disappeared quickly and the bout had ended within 2 to 3 weeks in 1978 .

He next reported in 1986, having had occasional mild clusters in the intervening 8 years, which he could readily control with ergotamine used for 2 or 3 weeks. However, for 2 weeks the pattern of his headaches had changed.

During this period he had experienced no less than 10 to 14 attacks of similar headache each day (see fig). Seven or eight were at night "waking me like clockwork at hourly intervals" and three or four occurred in waking hours. Attacks were much briefer, many lasted 5 to 10 minutes; the longest persisted for $\mathbf{4 0}$ minutes. He described a stabbing and throbbing pain in the left forehead and eye, radiating to the left temple, side of nose, upper jaw and, when severe to the ear and occiput. Associated with this intense pain were localised tenderness and a watering bloodshot eye, congested stuffy nostril and profuse sweating over the same side of the forehead and cheek. He had eliminated alcohol and taken meptazinol, paracetamol and asprin preparations without relief Movements of the neck and local pressure had not been noticed to trigger attacks. $\mathrm{He}$ had no visual disturbance, and was nauseated in only the most severe episodes, but he had never vomited.

A diagnosis of chronic paroxysmal hemicrania was suspected; however, he was started on $1 \mathrm{mg}$ ergotamine tartrate suppositories 8 hourly as a base line with which to compare the future use of indomethacin. Ergotamine afforded but partial relief for 4 days; his headaches then returned with a vengeance (fig). After 2 weeks he was given indomethacin $25 \mathrm{mg}$, tds, and symptoms rapidly declined in intensity and frequency. The dose was increased to $25 \mathrm{mg}$, qds, and symptoms vanished after 22 days. He has been in total remission, off drugs for 7 months.

His illness has thus shown three phases: classic migraine age 16 to $20 \mathrm{yr}$, episodic cluster headache age 48 to $57 \mathrm{yr}$, chronic paroxysmal hemicrania age $58 \mathrm{yr}$ (a single attack so far)

The content of chronic paroxysmal hemicrania attacks is very similar to cluster headache. There is intense, short lived strictly unilateral pain centred on the orbit and temple, associated with a red watering eye and blocked or running nostril. In both syn- dromes the victim is restless and distraught and will pace the floor or leave the house, in vivid contrast to the enforced immobility which characterises migraine.

The characteristics of chronic paroxysmal hemicrania are: (a) greater frequency of attacks, usually more than 8 per $24 \mathrm{~h}$; (b) briefer duration than cluster attacks 5 to 30 min as compared to 30 to $120 \mathrm{~min}$; (c) a much higher incidence in women; (d) a complete therapeutic response to indomethacin.

Unusual features in our patient are: he is male; the onset of chronic paroxysmal hemicrania age $58 \mathrm{yr}$ is late (mean was 29 in Sjaastad's series; ${ }^{7}$ headaches responded to indomethacin but, did not recur when the drug was stopped. In the light of this case and one other unreported patient a 17 year old girl with an episodic course (JMSP), we suggest a new classification, as in cluster headache there may be two types:

Chronic paroxysmal hemicrania

1 episodic-uncommon, perhaps $5 \%$ of cases

2 chronic-common, perhaps $95 \%$.

\section{Cluster headaches}

1 episodic, common (90\%)

2 chronic, uncommon $(10 \%)$

Finally, it is of interest that one patient has had three distinctive and apparently separate headache syndromes at three different periods of his life. The aetiology of both chronic paroxysmal hemicrania and cluster headache remain obscure. There is evidence (reviewed in refs 10,11 ) in cluster headache of a peripheral paresis of the sympathetic nervous system, probably located at the third neuron in the pericarotid plexus. This explains the miosis, ptosis, conjunctival injection and nasal stuffiness. Lachrymation and rhinorrhoea, however, raise the question of parasympathetic (cholinergic) hyperactivity, but evidence for this is insubstantial. ${ }^{10}$ Similar mechanisms are likely to obtain in chronic paroxysmal hemicrania, but the timing, frequency and therapeutic responses are distinctive. ${ }^{1112}$ The occurrence of the three disorders at separate times in a 40 year period in one patient strengthens the case for a common susceptibility to "neurovascular headaches"13 and perhaps for a central that is, hypothalamic disorder of threshold which dictates the pattern and timing of attacks and the remissions.

SHS PEARCE*

JGC COX

JMS PEARCE

Department of Neurology, Hull Royal Infirmary,

Hull HU3 $2 J Z$

and The Medical School,*

University of Newcastle upon Tyne,

$U K$
References

1 Kudrow L. Cluster Headache, Mechanisms and Management. Oxford, O.U.P. 1980:10-12. ఝ

2 Pearce JMS. Chronic migrainous neuralgia Brain 1980;103:149-59.

3 Ekbom K. Clinical comparison of cluster header ache and migraine. Acta Neurol Scand (supp 41) $1970 ; 46: 1-48$

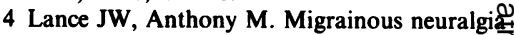
or cluster headache? $J$ Neurol Ser 1971;13:401-14.

5 Anderson PG. Migraine in patients with clusteon headache. Cephalalgia 1985;5:11-16.

6 Sjaastad O, Russell D, Saunte C, Horven Chronic paroxysmal hemicrania. VI. Precip itation of attacks. Cephalalgia 1982;2:211-14.

7 Sjaastad O, Apfelbaum R, Caskey W et a Chronic paroxysmal hemicrania (CPH). Thể clinical manifestations. A review. Upsaala $\mathrm{F}$ Med Sci (suppl) 1980;31:27-33.

8 Rapoport AM, Sheftell F, Baskin SM. Chronieparoxysmal hemicrania-case report of the second known definite occurrence in a male Cephalalgia 1981;1:67-9

9 Jorkowitz S. Chronic paroxysmal hemicrania and cluster. Ann Neurol 1978;4:389-94.

10 Vijayan N, Watson C. Peripheral autonomic abnormalities in cluster headache. In Mathew NT, ed. Cluster Headackle $\overrightarrow{-}$ Lancaster. MTP Press. 1984:45-56.

11 Pearce JMS. The enigma of migrainous ituralgia (syn cluster headache). The Physifait India 1986;3:142-9.

12 Petty RG, Rose FC. Chronic paroxys hemicrania: the first reported British cased Br Med J 1983;286:438.

13 Graham JR. The relation of cluster headaine to migraine: In Mathew NT, ed. Cly Headache, Lancaster. MTP Press. 1984:79-87.

Accepted 26 June 1987

\section{Relief of common migraine by exercise}

Sir: It is generally believed that exercis aggravates vascular headache of anf kind. ${ }^{12}$ I wish to report a case in which the effect was quite the contrary.

A 44 year old male physician had been suffering for 6 years from attacks of a dulE boring headache in the left temple. Thê bouts occurred between one and four time a month, usually on waking up in week ends, and lasted until the next morning occasionally for 2 or 3 days. The attacks were often triggered by lack of sleep, a few glasses of red wine, or both. Visual or othep prodromes never occurred, and apart from 7 faint nausea there were no associated feaㅡㅡㅁ tures. Pressing the superficial temporai artery gave some sort of relief but did nop end the attacks; aspirin was ineffective. HiS 